\title{
Identidades políticas emergentes: el profesorado indígena como sujeto colectivo en México y Colombia (Periodo colonial-1990) $^{1}$
}

\author{
Emerging political identities: indigenous teachers as a collective subject in \\ Mexico and Colombia (Colonies- 1990)
}

\begin{abstract}
Identidades políticas emergentes: o professorado indígena como sujeito coletivo no México e na Colômbia (Colônias-1990)
\end{abstract}

\author{
Diana Cecilia Rodríguez Ugalde ${ }^{2}$ \\ Universidad Autónoma de San Luis Potosí (México)
}

Recepción: 19/06/2017

Evaluación: 22/07/2017

Aceptación: 24/08/2017

Artículo de Reflexión

DOI: https://doi.org/10.19053/01227238.7557

\begin{abstract}
RESUMEN
El artículo trata sobre la historia Estado nacional homogéneo, previo a sociopolítica de la educación para/de los la década de 1990. Se hizo un recuento pueblos originarios y la construcción de histórico siguiendo la metodología de la identidades del profesorado indígena en México y Colombia; específicamente, sitúa el periodo que va de la Colonia al historia comparada, propuesta por Bloch, con base en documentos académicos, tesis, leyes, decretos y declaraciones de
\end{abstract}

1 Este trabajo forma parte de un proyecto de investigación doctoral sobre la construcción de la identidad del profesorado indígena en el llamado "Estado plural". La temática del artículo pretende responder a las siguientes preguntas de investigación: 1) ¿cuáles fueron los procesos sociopolíticos que ocurrieron de la época colonial a la constitución republicana que dieron forma a la educación indígena en México y Colombia?, 2) ¿cuáles fueron los acontecimientos sociopolíticos después de la conformación de los Estados nacionales homogéneos de México y Colombia, previos a la conformación de los Estados nacionales multiculturales, que orientaron a algunas de las actuales propuestas de educación indígena y de formación del profesorado? 3) ¿cómo emergen las identidades del profesorado indígena en estas relaciones? Esto nos permitirá comprender qué representan los profesores y las profesoras indígenas desde cada propuesta, al ser agentes políticos en la construcción de las identidades de sus alumnos. Para lograr este estudio tuve apoyo por parte del Consejo Nacional de Ciencia y Tecnología -CONACYT- con una beca nacional y mixta.

2 Profesora de la Facultad de Psicología de la Universidad Autónoma de San Luis Potosí (UASLP). Estudiante del Doctorado en Estudios Latinoamericanos en Territorio, Sociedad y Cultura, en la Facultad de Ciencias Sociales y Humanidades de la UASLP. Maestra en Psicología con orientación en el área de Educación y Sociedad por la misma institución. Licenciada en Psicología por la UASLP. Áreas de formación: Psicoterapia con enfoque sistémico, Psicología educativa, y más recientemente en Antropología y Sociología de la Educación. Líneas de investigación/intervención: Formación del profesorado, Identidad del profesorado indígena, Educación inclusiva y Educación para/por los pueblos originarios. Email: psic.diana.rdz.ugalde@hotmail.com 
ambos países que tratarán la temática. Al inicio de este periodo es posible distinguir ampliamente el interés, en ambas regiones, de concretar la unidad nacional a través de un modelo de nación mestiza, donde la identidad cultural, política y social de los pueblos originarios fue anulada, y la educación -dirigida por la Iglesia/Estado o por el Estadofue una estrategia para ello. A mediados del siglo $\mathrm{XX}$, ocurren en los territorios tensiones entre los movimientos sociales de los pueblos originarios y los Estados nacionales homogéneos ${ }^{3}$. Se hace especial énfasis en la propuesta educativa para los pueblos originarios y de formación del profesorado indígena de ambos Estados, y en la agencia de estos como sujetos colectivos que se reivindican ante el Estado. Así, las identidades del profesorado indígena emergen, principalmente, en la tensión entre la fuerza del Estado y la resistencia de los pueblos originarios, como sujetos políticos.

Palabras clave: educación bilingüe; formación de docentes; identidad cultural; movimiento social; Revista Historia de la Educación Latinoamericana.

\section{ABSTRACT}

This article is about the sociopolitical history of education for native peoples and the construction of identities of indigenous teachers in Mexico and Colombia. This research covers the period from the Colony to the homogeneous nation-state [1] prior to the 1990s. A historical recount was carried out by means of the comparative-historical methodology, proposed by Bloch, based on academic documents, of both countries, such as theses; laws; decrees; and declarations. At the beginning of this period, it is widely evident the interest of both regions to achieve the national unity through a mestizo nation model, where the education -directed by the Church / State or by the State- was the strategy to nullify the cultural, political, and social identity of the native peoples. In the middle of the 20th century, tensions took place between the social movements of the indigenous peoples and the homogeneous nationstates. Special emphasis is placed on the educational proposal for indigenous peoples, and indigenous teachers training of both States, and on the diligence of those peoples to vindicate themselves, as collective subjects before the State. In this way, the identities of the indigenous teachers emerge, mainly, in the tension between the strength of the State and the resistance of the indigenous peoples, as political subjects.

Keywords: bilingual education; teacher training; cultural identity; social movement; Journal History of Latin American Education.

\section{RESUMO}

O artigo trata da história sócio-política da educação de/para os povos originários e a construção de identidades do professorado indígena no México e na Colômbia; especificamente, recorta o período que vai da Colônia ao Estado nacional homogêneo, anterior à década de 1990. Fez-se um resgate histórico seguindo a metodologia da história comparada, proposta por Bloch, com base em documentos acadêmicos, teses, leis, decretos e declarações de ambos países que trataram a temática. No início deste período é possível distinguir amplamente o interesse, em ambas regiões, de concretizar a unidade nacional por meio de um modelo de nação mestiça, na qual a identidade cultural, política e social dos povos originários foi anulada, e a educação - dirigida pela Igreja/Estado ou pelo Estado - foi uma estratégia para isso. Em meados do século $X X$, ocorrem, nos territórios, tensões entre os movimentos sociais dos povos originários e os

3 Luis Villoro, "Del Estado homogéneo al Estado plural". En Estado plural, pluralidad de culturas (México: UNAM/Paidós, 1998 ), 34. 
Estados nacionais homogêneos. Termina colocando especial ênfase na proposta educativa para os povos originários e de formação do professorado indígena de ambos Estados, e na agência dos povos originários e do professorado indígena como sujeitos coletivos que se reivindicam perante o Estado. Assim, as identidades do professorado indígena emergem, principalmente, na tensão entre a força do Estado e a resistência dos povos originários como sujeitos políticos. Palavras-chave: educação bilíngue; formação de docentes; identidade cultural; movimento social; Revista História da Educação Latinoamericana.

Contextualización: Idioma Maya Popti'

Contextualizador: Aurelio Domingo Hurtado Montejo

Ministerio de Educación de Guatemala

YITZ'ATILAL

Hune' txumba'lil ti' xhtzotenhe yib'anhiloj hej kuyb'anile yetwanoj hej payat konhob' b'oj hej yik'ti'alil hej kuywahom payq'inalil yet konhob' México b’oj konhob' Colombia; cha' elwanoj tzet $\mathrm{xu}$ yalanhto mach chulikoj heb'ya' wes masanto yet xi' yip yik'al heb'ya' wes yet hej hab'ilal 1990. Xb'isb'alotoj xin yik'ti'al hej konhob' haka' txumb'alile icheb'ilkanh yu ya' kuywahom Bloch sb'ih itz'atnheb'il yinh hej kuyb'anile hum, txumb'anile hum, b'oj hej chejb'anile hum yet kab' konhob' tu' (México b'oj Colombia).

Yichob'anil hej hab'ilal xhb'ina $t^{\prime}$, hab'an stxumloyi chub'ilta hanhe yitz'atneb'anil yik'ti'al heb'ya' wes yetwanoj ye yi'ini yip, mach xin x'a'lo yip yik'al hej payat konhob' ayxatik'a yalanhto mach chulikoj heb'ya wes tu'; haxkam ha' tu' xin smunil hej yatut tiyoxh b'oj hej kuyum yet payxa $\mathrm{tu}^{\prime}$.

Slahob'alxa hune' kuyb'anile ti', xin cha'pax b'inahoj tzet xu stxumni sb'a sk'ul heb'ya' kuywahom payat q'inale tzet chu ya'lopax smay sq'inal hej payat konhob' yinh tzet chu hej Estado tet anma yunheb'al ya'lo smay spixan yik'al. Haktu' xin xu yi'nikanh yip hej payat konhob' yul sat hej Estado.

Hej tzoti' ch'elwani: Kuyb'anile yul kab' ab'xub'ale; skuyb'anil hej kuywahom; yetwabijilal hej konhob'; yijlob'anil yu hej tzetet; Pujb'ab'al Txumb'ale Yib'anhiloj Kuywab'al Hum yet Ab'ya' Yala'

\section{INTRODUCCIÓN}

En algunos países de América Latina, desde la última década del siglo pasado, se ha iniciado una modificación jurídica relacionada con el reconocimiento de las diferencias culturales y étnicas. Esto ha permitido que países como México, Colombia, Ecuador y Bolivia transiten jurídicamente de Estados nacionales homogéneos a Estados nacionales multiculturales, en los cuales, se reconoce la diversidad de culturas y grupos étnicos o pueblos originarios que coexisten y se relacionan en el espacio nacional. Este hecho permite preguntar sobre dos situaciones y procesos: ¿cuáles fueron las condiciones históricas que posibilitaron este cambio jurídico de reconocimiento de la multiculturalidad en la composición nacional? y ¿cómo han incidido estas condiciones históricas en la educación de/para los pueblos originarios y, con ello, en la emergencia de acciones para la conformación de identidades del profesorado indígena? De 
esta forma, el análisis se centra en el campo educativo, particularmente en los proyectos orientados a la formación de profesionistas docentes que pertenecen a los pueblos originarios. Para ejemplificar este análisis, se toman los casos de Colombia y de México.

El recorrido histórico que se presenta es, por el poco espacio que se tiene, breve: abarca un periodo que compete de la Colonia hasta antes de 1990. Lo que interesa es trazar una línea de continuidad histórica entre las relaciones del Estado y los pueblos originarios en el espacio sociopolítico educativo. Se fundamenta en el paradigma interpretativo con base en el análisis de contenido; recupera metodológicamente la propuesta comparativa de tipo documental (artículos académicos, leyes, decretos, libros, tesis) de Bloch. ${ }^{4}$ Junto con este autor, se entiende que la comparación en la historia es posible entre "dos o más fenómenos que a primera vista parecen presentar ciertas analogías entre sí, describir sus curvas evolutivas, constatar las similitudes y las diferencias y explicarlas en la medida de lo posible. Es necesario, por tanto, que existan dos condiciones para que, históricamente hablando, haya comparación: una cierta similitud entre los hechos observados (...) y una cierta diferencia entre los medios en que ambos han tenido lugar". Así, se privilegian dos dimensiones de análisis: a) la relación entre el Estado y los pueblos originarios, precisamente sus políticas implementadas sobre educación indígena o para los pueblos originarios y, b) surgida de esta relación, la emergencia del profesorado indígena como sujeto con identidad política. El trabajo fue realizado siguiendo los siguientes pasos: lectura minuciosa de los documentos, clasificación de eventos y transiciones históricas en fichas de lectura a partir del análisis de contenido, sistematización de datos en programa Atlas.ti, esquematización de los hechos, escritura del documento.

El análisis presentado considera que el tránsito de Estado nacional homogéneo a uno multicultural o culturalmente plural, no ha ocurrido a través de un proceso lineal, del Estado hacia los pueblos originarios. ${ }^{5} \mathrm{Al}$ contrario, los movimientos étnicos y magisteriales han hecho posible que, mediante sus luchas de reconocimiento, los Estados modificarán sus respectivas constituciones. ${ }^{6}$ Así, la lucha étnica por el derecho a la educación ha sido un componente sobresaliente en el cambio constitucional del Estado que ocurre en ambos países iniciada la década de 1990. En síntesis, en este trabajo se aborda el análisis de la conformación de profesionistas docentes indígenas atendiendo históricamente, por un lado, las políticas gubernamentales de educación indígena y, por otro, las luchas sociales de los pueblos originarios que anteceden al tránsito hacia el Estado multicultural. Una categoría relevante en el análisis es la de identidad, por ello, se inspeccionan las maneras en que se configura a partir de las tensiones entre el Estado nacional homogéneo y los movimientos de lucha de reconocimiento étnico, en la comprensión de que el contexto histórico forma parte del nivel macropolítico de los procesos de construcción de la identidad

4 Marc Bloch, "A favor de una historia comparada de las civilizaciones europeas", en Historia e historiadores, trad. Francisco González García (Madrid: Akal, 1999), 115-117.

5 Willem Assies, et al, "Los pueblos indígenas y la reforma del Estado en América Latina”, Papeles de Población, 31 (2002): 96.

6 Pablo Gentili, Pedagogía de la igualdad. Ensayos contra la educación excluyente (Buenos Aires: Siglo XXI Editores-Clacso, 2011), 108. 
de este sujeto colectivo. Se considera es una identidad profesional docente indígena inédita, emergente, que surge bajo la transición de Estado que se ha mencionado; constata que emerge como una estrategia política desde distintos sitios -el Estado, los pueblos originarios- y cambia acorde a los contextos políticos nacionales e internacionales. Así, el artículo abona a la discusión sobre las nuevas formas de construcción de identidades culturales en América Latina.

\section{La educación indígena (del periodo colonial a la conformación de Estados nacionales homogéneos): los casos de México y Colombia}

La desigualdad social en la que se encuentran los pueblos originarios ha sido una constante desde la llegada de los españoles. Ubicados en los últimos peldaños de la escala social, los pueblos originarios -aunque no fueron los únicos como actualmente lo muestran diversos investigadores al visibilizar la presencia de la población africana esclavizada- asumieron su identidad en esta relación de desigualdad social, política y económica durante la Colonia, a la que pasó a sumarse la cultural durante la República. ${ }^{7}$

Considerados en un inicio como salvajes o bárbaros "sin alma", fueron tratados en el nivel inferior de la estratificación social creada por la categoría de raza y etnia. Las misiones de evangelización durante la colonia en el actual territorio de América Latina -principalmente los jesuitas al sur del continente, los dominicanos y capuchinos en la Nueva Granada, y los franciscanos en la Nueva España-, ayudaron al ordenamiento de la estratificación social. ${ }^{8}$ De este modo, las misiones introdujeron en los pueblos originarios otras concepciones del mundo a través de la educación formal, la educación de oficios y la enseñanza religiosa. No obstante, se respetó la diversidad lingüística al servir como vínculo para la evangelización. A pesar de ocupar un lugar inferior en las jerarquías coloniales, a varios pueblos originarios se les permitió mantener ciertas instituciones sociales relacionadas con su cultura. ${ }^{9}$

La esclavitud fue un eje determinante y articulador de las relaciones asimétricas de la colonia, ya sea en la construcción de las ciudades o en la mita, que en repetidos casos disfrazó al trabajo forzado en las minas o en el campo. Esta dinámica esclavista hacia los pueblos originarios llegó a su abolición en 1542, con las Leyes Nuevas. ${ }^{10}$ A pesar de las relaciones asimétricas, en los territorios de América Latina ocurrieron rebeliones por parte de los pueblos originarios, como los referidos por Moreno ${ }^{11}$ en la zona de Quito. Frente a estas relaciones de desigualdad política, los pueblos originarios ejercieron un papel importante durante los levantamientos independentistas en el territorio colonial.

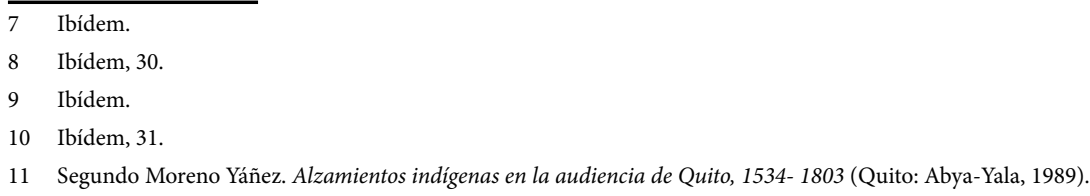


El objetivo de los dirigentes de los territorios independientes en esta región, una vez que dejaron de ser colonias, fue la cohesión nacional y, con ello, generar un nuevo orden libertario. Sin entrar mucho en detalle, quiero comentar algunos puntos. Esta búsqueda de un nuevo régimen tuvo como referente principal a la cultura occidental francesa e inglesa por considerarla civilizada -hecho que muestra con bastante claridad José Luis Romero. ${ }^{12}$ Sin embargo, este modelo se amplió a diversas áreas de la vida social -económica, política, cultural. Los dirigentes de la nueva organización sociopolítica, convencidos de la idea de razón y progreso -basada en el positivismo y evolucionismo occidental- como el camino que dirigiría a la modernidad, vieron como un lastre a los pueblos originarios, quienes, según la ideología perenne en ese momento, portaban el estandarte del retraso que obstaculizaba la modernidad..$^{13}$ De este modo, en décadas posteriores, durante el auge del indigenismo, se aludió a los gobiernos a acabar con "el problema indígena"14.

Este ideal progresista en el reciente orden republicano, nuevamente situó trabas "a la apertura de canales de movilidad social para las personas indígenas". ${ }^{15}$ El ideal significó una justificación de la violencia contra las identidades que se alejaban del modelo francés e inglés, es decir, aquellas identidades de los pueblos originarios y, en muchos casos, también de la población afrodescendiente que cohabitaba la región. Veamos la situación de Colombia ante este ideal. En Colombia, desde la primera parte del siglo XIX, la Iglesia se encontraba inmersa en los asuntos educativos de la República, tanto en el ámbito público como privado -en escuelas, colegios religiosos y universidades. ${ }^{16}$ El Estado, en concordato con la Iglesia, planteó en la educación el propósito de formar a ciudadanos en las áreas humanísticas y técnicas ${ }^{17}$, para lo cual otorgó recursos. ${ }^{18}$ En 1870 el Estado desarrolló una Reforma educativa de tipo radical, que tenía el fin de desplazar a la Iglesia del ámbito educativo, bajo los principios de laicidad, gratuidad y obligatoriedad; con esta reforma fue creada la Dirección Nacional de Instrucción Pública que se anexó al Ministerio del Interior. Sin embargo, la reforma fracasó debido a la oposición de los grupos conservadores y de la Iglesia. ${ }^{19}$

A finales del siglo XIX, el Estado colombiano se enfrentó a una situación económica y social difícil a consecuencia de las guerras civiles que ocurrieron. Estos acontecimientos llevaron a que el Estado, en 1887, firmara un concordato con el Vaticano, donde asignaba a este la dirección e impartición de la enseñanza a toda la población del territorio nacional, a la vez que creó el Ministerio de

12 José Luis Romero. "Las ciudades burguesas", en Latinoamérica: las ciudades y las ideas, $5^{\mathrm{a}}$ ed. (México: Siglo XXI Editores, 2001), 247-318.

13 Guillermo Bonfil Batalla, México profundo (México: CONACULTA, 1990), 53.

14 Ibídem, 92.

15 Néstor López. La educación de los pueblos indígenas y afrodescendientes. Informe sobre tendencias sociales y educativas en América Latina 2011 (Buenos Aires: Instituto Internacional de Planteamiento de la Educación IIPE-UNESCO, 2011), 34.

16 Carlos Medina Betancur. "La autonomía educativa indígena en Colombia", Vniversitas, 124 (2012): 278.

17 Carolina Hirmas, et al., Políticas educativas de atención a la diversidad cultural: Brasil, Chile, Colombia, México y Perú, eds. Pablo Marambio (Santiago: OREALC/UNESCO, 2005), 291.

18 Sonia Mercedes Rodríguez Reinel. "La política educativa (etnoeducación) para los pueblos indígenas en Colombia a partir de la Constitución de 1991” (Tesis de Maestría en Antropología, Universidad Nacional de Colombia, 2011), 47.

19 William Malkún Castillejo. "La reforma educativa de 1870 en el Estado soberano de Bolívar", en Revista Amauta, 1, no. 15 (2010): 137-156. 
Educación Nacional, que tuvo mayor presencia institucional en lo educativo a partir de $1927 .{ }^{20}$ En el ámbito de la educación para los pueblos originarios, la Iglesia se encargaba de la enseñanza del castellano, la cristiandad y el aprendizaje de prácticas económicas civilizadas orientadas al ejercicio de la soberanía nacional. ${ }^{21}$ En 1886, conforme a las políticas educativas planteadas en la Constitución, la Iglesia confirmó el objetivo nacional de integrar a los pueblos originarios y afrodescendientes a la "civilización". ${ }^{22}$

En ese tiempo, en América Latina comenzó a plantearse un modelo de identidad cultural y social propio, resumido en la idea de identidad mestiza. ${ }^{23}$ Este nuevo referente continuó confirmando la invisibilidad y el rechazo por parte de la hegemonía hacia los pueblos originarios, ya que la ideología gestora occidental de la modernidad y el progreso no fue cuestionada. En este contexto histórico, las instituciones creadas por el Estado en América Latina se apegaron al interés de consolidar una nación mestiza, dentro de ellas, la institución educativa. Aun cuando el caso mexicano presenta diferencias con el caso colombiano, debido a que en México el Estado fue el encargado de educar formalmente a los pueblos originarios, en ambos lugares el interés por consolidar una nación homogénea rigió la ideología y la acción social en el ámbito educativo. Ambas regiones coincidían en lo político; es decir, en las prácticas sistemáticas de ejercer el poder, de asimilar, que se traducían en exclusión e invisibilidad de los pueblos originarios. En México, por ejemplo, se fundó la "casa del estudiante indígena" también llamada "internado indígena" - en 1926, con el fin de impartir educación primaria y la enseñanza de algún oficio agrícola, manual o industrial a jóvenes varones pertenecientes a pueblos originarios con alta densidad demográfica, para que ellos volvieran a sus comunidades y enseñaran lo aprendido. ${ }^{24}$ En el periodo cardenista, se apoyó la creación del Programa Nacional de Educación Bilingüe, que tenía el fin de continuar con la integración pero por medio del uso de las lenguas vernáculas y el castellano. ${ }^{25} \mathrm{El}$ interés de la integración nacional homogénea se reiteró entre los gobiernos de distintos países de América Latina durante el Primer Congreso Indigenista Interamericano en el año de 1940.

No obstante, existe información sobre la participación de los pueblos originarios en los procesos educativos orientados hacia ellos en México, desde inicios del siglo XX, cuando el asunto educativo aún no se concentraba en manos del poder del gobierno. Relacionado con ello, Baronnet ${ }^{26}$ nos narra que:

20 Sonia Mercedes Rodríguez Reinel, "La política educativa (etnoeducación) para los pueblos indígenas en Colombia a partir de la Constitución de 1991” (Tesis de Maestría en Antropología, Universidad Nacional de Colombia, 2011), 30.

21 Ibídem.

22 Ibídem.

23 Néstor López, La educación de los pueblos indígenas y afrodescendientes. Informe sobre tendencias sociales y educativas en América Latina 2011 (Buenos Aires: Instituto Internacional de Planteamiento de la Educación IIPE-UNESCO, 2011), 291.

24 María Bertely Busquets, "Educación indígena del siglo XX en México", en Un siglo de educación en México, tomo II, edr. Pablo Latapi Sarre (México: Consejo Nacional para la Cultura y las Artes/ Fondo de Cultura Económica, 1998), 76.

25 Carolina Hirmas, et al., Políticas educativas de atención a la diversidad cultural: Brasil, Chile, Colombia, México y Perú (Santiago: OREALC/UNESCO, 2005), 409.

26 Bruno Baronnet, Autonomía y educación indígena: las escuelas zapatistas de la Cañada de la Selva Lacandona, México. (Tesis de Doctorado en Ciencia Social, Colegio de México y Université Sorbonne Nouvelle París III, 2009), 18-19. 
En los primeros años posteriores a la Revolución mexicana se abrió una época de cambios favorables para la autonomía de las comunidades indígenas en algunos estados del país, para que estas participaran e incidieran en la selección y la vigilancia de los maestros. Así, el ejercicio de cierto nivel de autonomía local en la gestión escolar precede a la concentración del poder educativo en manos del gobierno federal en el siglo XX.

Sin embargo, con la consolidación del cuerpo institucional educativo, sea por la vía estatal o clerical, las políticas de los Estados nacionales relacionadas con el asunto educativo se caracterizaron por ser asimiladoras. Es decir, buscaban integrar y asemejar a los pueblos originarios a la cultura y nacionalidad hegemónica, someter a las identidades plurales a la idea de identidad nacional. ${ }^{27}$

En 1948 se creó el Instituto Nacional Indigenista (INI) en México. El INI, en sus inicios, fue una institución que articuló las acciones de distintas instancias públicas relacionadas con los asuntos de los pueblos originarios, pero desde el indigenismo integrador. De este modo muestran Sosa y Henríquez ${ }^{28}$ al señalar que el INI se regía por la política de "integrar a los indígenas a la cultura nacional. El camino para lograrlo [era] su aculturación a partir de la acción indigenista en las regiones interculturales, también conocidas como regiones de refugio". Asimismo, señalan el objetivo institucional que guiaba los proyectos y acciones del INI desde su fundación hasta 1970: “inducir el cambio cultural de las comunidades y promover el desarrollo e integración en las regiones interculturales a la vida económica, social y política de la nación" ${ }^{29}$

En ese mismo periodo, frente a las experiencias anteriores de educación indígena a través de la "castellanización directa" o monolingüista -sea a través de la evangelización o mediante los internados en México y Colombia-, y ante la recomendación de la UNESCO en 1951 de usar la lengua vernácula como vehículo de alfabetización de los pueblos originarios ${ }^{30}$, en varios países de América Latina se desarrollaron nuevos programas educativos para este sector de la población. En México se formalizó el Sistema de Educación Bilingüe- Bicultural por parte de la SEP (1963), iniciado en los Altos de Chiapas en 1951 por el INI. ${ }^{31}$ En 1952, el Instituto Lingüista de Verano participó con el gobierno mexicano en el estudio de las lenguas originarias de la región. ${ }^{32}$

En este tenor, la SEP, debido a la falta de instituciones para la formación docente en el medio indígena, creó en 1963 el Servicio Nacional de Promotores Culturales y Maestros Bilingües, que formaba a pertenecientes pueblos originarios con el fin de

27 Rodolfo Tuirán y Susana Quintanilla, 90 años de educación en México (México: FCE, 2012), 17, 37, 67.

28 Margarita Sosa y Cristina Henríquez, Instituto Nacional Indigenista- Comisión Nacional para el Desarrollo de los Pueblos Indígenas 1948-2012 (México: CDI, 2012), http://www.cdi.gob.mx/dmdocuments/ini-cdi-1948-2012.pdf (7 febrero, 2016), 7.

29 Ibídem.

30 Juan Bello Domínguez, "El inicio de la educación bilingüe bicultural en las regiones indígenas en México", en Memoria electrónica del X Congreso Nacional de Investigación Educativa COMIE, línea temática 9: Historia e historiografía de la Educación, eds. Susana Quintanilla Osorio y María Candelaria Valdés Silva (Veracruz, México, 2009), 5.

31 Ibídem, 8.

32 Ibídem, 3. 
que promovieran la cultura nacional a través de la lengua vernácula como medio para enseñar el castellano. ${ }^{33}$ Además de las acciones específicas para la educación de los pueblos originarios, la creación y tiraje de los libros de texto gratuito y los cuadernos de trabajo en 1959 vino a acrecentar la hegemonía cultural del Estado nacional homogéneo y a generar otro medio para avanzar en el objetivo de la integración nacional. ${ }^{34}$

En Colombia, el ámbito de la educación indígena tomó matices que le distinguen abruptamente de México, aunque -como ya se mencionó- el objetivo era el mismo: la integración nacional. A pesar de que en 1936 el Ministerio de Educación Nacional, dirigido por Luis López de Mesa, intentó delimitar el poder y las funciones de la Iglesia con base en la Reforma Acto Legislativo 1, la educación orientada hacia los pueblos originarios siguió igual, y la Iglesia mantuvo su dominio como institución educativa. El Estado quedó en el ámbito educativo como una instancia de inspección y vigilancia. ${ }^{35}$ En Colombia, al igual que en México, se creó el Instituto Indigenista de Colombia en 1942, al cual antecedió el Instituto Etnológico Nacional en 1941. ${ }^{36}$ Sin embargo, el tipo de educación Iglesia-docente ${ }^{37}$ no delimitó su dirección.

En otro intento del Estado por romper la hegemonía de la Iglesia católica, apostólica y romana en la educación para los pueblos originarios dirigida por ella a finales de la década de 1960, el Estado firmó un convenio con el Instituto Lingüístico de Verano (ILV), a través de la Dirección de Asuntos Indígenas, con el supuesto fin de estudiar las lenguas originarias. Sin embargo, la incidencia del ILV no se delimitó a este estudio, sino que influyó en la cultura de los pueblos originarios a través de la evangelización. ${ }^{38}$ Las propuestas educativas de la Iglesia-docente y del ILV se distanciaron de la realidad y la cultura de los pueblos originarios, y se fundaron en la castellanización y evangelización. A diferencia de México, en Colombia se cuestionó el papel de la escuela y las formas tradicionales de enseñanza para los pueblos originarios hasta la década de 1970, por parte de los pueblos originarios, a raíz de las luchas por el territorio que iniciaron en 1960 los pueblos originarios del Cauca. ${ }^{39}$

Traer este periodo al análisis, permite situar contextualmente las realidades que vivieron los pueblos originarios, y comprender los movimientos de contrainsurgencia que han dado origen al cuestionamiento del paradigma homogeneizante e integracionista -aun cuando comenzó en otras latitudes

33 Ibídem, 4.

34 Rodolfo Tuirán y Susana Quintanilla, 90 años de educación en México (México: FCE, 2012), 42.

35 Sonia Mercedes Rodríguez Reinel, "La política educativa (etnoeducación) para los pueblos indígenas en Colombia a partir de la Constitución de 1991” (Tesis de Maestría en Antropología, Universidad Nacional de Colombia, 2011), 54.

36 Francois Correa Rubio, "La modernidad del pensamiento indigenista y el Instituto Nacional Indigenista de Colombia", en Maguaré, No. 21 (2007): 27.

37 Axel Rojas y Elizabeth Castillo, Educar a los otros: políticas educativas y diversidad cultural en Colombia (Popayán: Universidad del Cauca, 2004), 63.

38 Juan Bello Domínguez, "El inicio de la educación bilingüe bicultural en las regiones indígenas en México", en Memoria electrónica del X Congreso Nacional de Investigación Educativa COMIE, línea temática 9: Historia e historiografía de la Educación, eds. Susana Quintanilla Osorio y María Candelaria Valdés Silva (Veracruz, México, 2009), 3.

39 Elizabeth Castillo y José Antonio Caicedo, La educación intercultural bilingüe: el caso colombiano (Buenos Aires: Fund. Laboratorio de Políticas Públicas, 2009), 19. 
mundiales de Europa y Estados Unidos por la inmigración y el racismo- y a las actuales demandas de reconocimiento, participación e inclusión de la heterogeneidad. ${ }^{40}$ Aunque en el periodo señalado ocurrieron cambios en los procesos de formación docente indígena de mano de los cambios dentro de la educación indígena, estos siguieron siendo acordes a los intereses políticos de los líderes hegemónicos.

El largo periodo de exclusión y de relaciones asimiladoras hacia los pueblos originarios, al entrar en el juego de estructura de clases desde su etnicidad con la sociedad nacional, en un sistema de dominación- sujeción ${ }^{41}$, los ha dejado en un lugar de invisibilidad y desconocimiento, por parte de la sociedad nacional hegemónica, sobre sus propias formas de comprender al mundo, a la vida y a ellos mismos, así como sus modos de organización política y social, además de sus culturas: han violentado sus identidades. Las propuestas que surgieron con el enfoque bilingüe-bicultural en México y el papel de la Iglesia-docente en Colombia, desde la enseñanza evangelizadora y castellanizadora, mantuvieron este desconocimiento sobre los pueblos originarios, acercando, en el caso de México, propuestas de formación docente que distaban de la cultura de los pueblos originarios en cuestiones que trascendieran la lengua y los elementos folclóricos, confirmando la relación interétnica. ${ }^{42}$

Esta relación asimétrica entre los pueblos originarios y la cultura hegemónica en el escenario educativo, generó inconformidad en los primeros, quienes, al igual que los grupos dominantes, encontraron en la educación una herramienta política, pero en sentido inverso al de la hegemonía: desde la reivindicación de sus identidades culturales y étnicas -entendida esta última como un tipo de organización jerarquizada entre distintos grupos al definir a la cultura en sus bases ideológicas y no como una reducción a los rasgos culturales estáticos, según retoma Cardoso de Oliveira ${ }^{43}$ de Barth.

De este modo, en coincidencia con el surgimiento de propuestas de formación docente por parte del Estado mexicano desde lo bilingüe-bicultural, y el reconocimiento por parte del Estado colombiano de una educación acorde a las culturas de los pueblos originarios, las décadas de 1960 y 1970 se caracterizaron, a nivel internacional -aunque más evidentemente en América Latina-, por la lucha por la visibilidad de los pueblos originarios junto a sus demandas educativas de participación y defensa de su identidad cultural más allá de la lengua, incluyendo a estas luchas al territorio, la organización y la autonomía. Es decir, la educación como un escenario para la acción política y social para

40 Daniel Solís y Patricia Martínez, Todos somos diferentes: pero aquí en la escuela somos iguales (México: Plaza y Valdés y UASLP, 2012), 78.

41 Roberto Cardoso de Oliveira, Etnicidad y estructura social (México: CIESAS, UAM, Universidad Iberoamericana, 2007 ), 84.

42 Gunther Dietz y Laura Selene Mateos Cortés, "Una década de educación intercultural en México: debates entre empoderamiento indígena y transversalización de la diversidad", en Educación intercultural a nivel superior: reflexiones desde diversas realidades latinoamericanas, eds. Sergio Enrique Hernández Loeza, María Isabel Ramírez Duque, Yumen Manjarrez Martínez y Aarón Flores Rosas (México: UIEP/UCIRED/UPEL, 2013), 22.

43 Roberto Cardoso de Oliveira, Etnicidad y estructura social (México: CIESAS, UAM, Universidad Iberoamericana, 2007), 50. 
el fortalecimiento de sus identidades. ${ }^{44}$ A partir de esta continuidad histórica -la resistencia de los oprimidos-, se logra avanzar hacia movimientos de los pueblos originarios con capacidad de interpelar al Estado o a la Iglesia con el fin de instalar su identidad cultural en la educación.

\section{Las luchas de los pueblos originarios en la década de 1970 en México y Colombia y el surgimiento de propuestas de formación docente diferenciadas}

La década de 1970 fue trascendental en el camino del reconocimiento de la composición pluricultural de algunas naciones de América Latina. El surgimiento de movimientos de pueblos originarios en algunos países de la región, como Bolivia, Colombia, Ecuador y Guatemala ${ }^{45}$, antecedido por los afrodescendientes en Estados Unidos, que aludían a derechos colectivos sociales, políticos, económicos, culturales y educativos, fue esencial para cuestionar la estructura de los Estados nacionales homogéneos y, con ello, evidenciar las prácticas vinculadas con el etnocidio. ${ }^{46}$ A este surgimiento social en México, Gutiérrez ${ }^{47}$ lo define como el movimiento intelectual indígena. En el marco de estas demandas, a nivel internacional se desarrolló la Declaración de Barbados I por parte de antropólogos y otros especialistas dedicados al tema indigenista, donde lanzaron una fuerte crítica al papel de los Estados, la Iglesia y los antropólogos, en su relación de dominación y paternalismo con los pueblos originarios. En esta Declaración se reconoció el derecho de los pueblos originarios al autogobierno y al desarrollo de sus propias instituciones. Seis años después, en 1977, se realizó la Declaración de Barbados II, en la cual, la voz principal fue de los dirigentes de los pueblos originarios. ${ }^{48}$

Si bien se cuenta con información que data que desde inicios del siglo XX, tanto en México ${ }^{49}$ como en Colombia ${ }^{50}$, existían levantamientos de los pueblos originarios contra las imposiciones territoriales, culturales y educativas del Estado, fue en la década de 1970 cuando más claramente iniciaron las demandas de los pueblos originarios sobre propuestas de escolarización que atendieran su realidad identitaria sociocultural, y que distaran de la alienación y el etnocidio que permeaba las propuestas desarrolladas hasta ese momento por parte del

44 Bruno Baronnet y Medardo Tapia Uribe, “Introducción: política, educación e interculturalidad”, en Educación e interculturalidad: política y políticas, eds. Margarita Velázquez Gutiérrez, Blanca Rebeca Ramírez Velázquez, Antonio García de León Griego, Elsa María Cross y Anzaldúa y Carlos Javier Echarri Cánovas (México: CRIM, 2013), 14.

45 Víctor Uribe-Urán, "Movimientos indígenas, constituciones, justicia plural y democracia en América Latina", en Justicia, política y derechos en América Latina, eds. Juan Manuel Palacio y Magdalena Candioti (Buenos Aires: Prometeo Libros, 2007), 85-87.

46 Agustín Lao Montes, "Cartografías del campo político afrodescendiente en América Latina”, Universitas Humanística, 68 No. 2 (2009): 218.

47 Natividad Gutiérrez, Mitos nacionalistas e Identidades Étnicas: los intelectuales indígenas y el Estado mexicano (México: Instituto de Investigaciones Sociales, UNAM, 2012), 178.

48 Guillermo Bonfil Batalla, et al., "La declaración de Barbados II y comentarios”, Nueva Antropología II, diciembre (1977): 110.

49 Bruno Baronnet, Autonomía y educación indígena: las escuelas zapatistas de la Cañada de la Selva Lacandona, México. (Tesis de Doctorado en Ciencia Social, Colegio de México y Université Sorbonne Nouvelle París III, 2009), 19.

50 Carolina Hirmas, et al., Políticas educativas de atención a la diversidad cultural: Brasil, Chile, Colombia, México y Perú (Santiago: OREALC/UNESCO, 2005), 286. 
Estado o la Iglesia-docente, en términos de educación básica y de formación docente. Frente a estas tensiones, tanto el Estado como los pueblos originarios de México y Colombia se vieron involucrados en la tarea de desarrollar propuestas para la educación de esta población y, por ende, para la formación del profesorado indígena.

En acciones que tomaron distancia de la lucha contrahegemónica pero que aumentaron las tensiones entre los pueblos originarios y el Estado, en México se creó la Dirección General de Educación Extraescolar en el Medio Indígena (DGEEMI) en 1971, que dependía de la SEP, la cual trabajó en colaboración con el INI para acercar los servicios educativos a los pueblos originarios del país y la formación de docentes indígenas. ${ }^{51}$ La formación docente se realizaba desde la validación de la identidad cultural hegemónica como una imposición en el ejercicio político.

No obstante lo anterior, desde las demandas de los pueblos originarios de México, se realizó en 1974, en Chiapas, el Primer Congreso Indígena "Fray Bartolomé de las Casas", y en 1975 el Primer Congreso Nacional de Pueblos Indígenas. ${ }^{52}$ En estos espacios, los pueblos originarios expresaron su realidad en la relación con el Estado. Así hicieron demandas sobre la tierra, el comercio, la salud y la educación. Sobre esta última, y en el ejercicio político en el campo educativo, evidenciaron la necesidad de una educación que atendiera y respetara su realidad cultural:

Vemos que la instrucción que se da en nuestras comunidades es muy pobre. En muchos lugares no hay escuela, pero donde hay, sólo llega hasta tercer año... Sólo se enseña a leer y a escribir, pero muchas veces después que los alumnos salen de la escuela se les olvida porque ya no tienen en qué leer... También vemos que la escuela como está, no es de acuerdo a nuestras necesidades, a nuestras costumbres, a nuestra cultura... Queremos que hablen nuestro idioma y que enseñen conforme a las necesidades de la Comunidad... Se necesitan escuelas para adultos... Que haya orientación para poder romper el círculo vicioso de explotación... ${ }^{53}$

Con ello, emergieron organizaciones lideradas por el profesorado indígena a mitad de la década de 1970 en México, por parte de maestros nahuas y mayas, como se muestra en el manifiesto conjunto "Conciencia y liberación étnica" y en la formación de la Organización de Profesionistas Indígenas Nahuas, A.C. (OPINAC).${ }^{54}$ Otro ejemplo es la Coalición de Maestros y Profesores Indígenas de Oaxaca (CMPIO), fundada en el año de 1974. En estas organizaciones emergentes, la búsqueda de una educación otra, cercana a las realidades culturales y políticas

51 Margarita Sosa y Cristina Henríquez, Instituto Nacional Indigenista- Comisión Nacional para el Desarrollo de los Pueblos Indígenas 1948-2012 (México: CDI, 2012), http://www.cdi.gob.mx/dmdocuments/ini-cdi-1948-2012.pdf (7 febrero, 2016), 11.

52 Gaspar Morquecho, El Congreso Diocesano Pastoral de la Madre Tierra (México: Agencia Latinoamericana de Información, 2014), http://www.alainet.org/es/active/70495 (19 de enero, 2016).

53 Ibídem.

54 Natividad Gutiérrez, Mitos nacionalistas e Identidades Étnicas: los intelectuales indígenas y el Estado mexicano (México: Instituto de Investigaciones Sociales, UNAM, 2012), 161. 
de los pueblos originarios, así como la búsqueda de un perfil del profesorado indígena, comprometido con la reivindicación política de los pueblos originarios, lideró a las asociaciones de profesores indígenas. ${ }^{55}$

En oposición a los procesos de aculturación y castellanización a los cuales se sometió a los pueblos originarios de México a través de la educación, estas organizaciones de intelectuales indígenas evidenciaron la falsedad de los argumentos que sostenían las acciones a las cuales calificaron de etnocidas. ${ }^{56}$ Fue así como los pueblos originarios, representados por los intelectuales indígenas en el campo educativo,

(...) de la misma manera como el Estado intentó socavar la identidad indígena mediante la aculturación y la castellanización de su programa de estudios, (...) encontraron, por medio de la educación, los mecanismos instrumentales para "regresar a nuestras culturas" $y$ "desarrollar nuestra cultura y ciencia". ${ }^{57}$

De este modo, mostraron la necesidad de una educación bilingüe para y por los pueblos originarios, por lo cual, en 1976, en Vicam, Sonora, surgió el proyecto de crear una educación que se considerara bilingüe y bicultural. Fue planteado en el Plan Nacional de Educación Bilingüe Bicultural por parte de la Alianza Nacional de Profesores Indígenas Bilingües (ANPIBAC), creada también en esta década. Sin embargo, aun cuando, como refiere Gutiérrez ${ }^{58}$, existiesen documentos firmados por los representantes del ámbito educativo del Estado y por los representantes de las asociaciones civiles de los pueblos originarios que generaron la iniciativa de una educación bilingüe y bicultural, donde se acordaba la constitución de un comité conformado por la Dirección General de Educación Indígena y el ANPIBAC, el Estado usurpó la iniciativa autónoma del ANPIBAC y se apropió de ella. Si bien las acciones de diversos colectivos del profesorado indígena en México no se definen por la sumisión, lo anterior es muestra de que ante las iniciativas autónomas sobre educación por parte de los pueblos originarios,

(...) las políticas oficiales han negado y evitado tradicionalmente concretar los proyectos indígenas que intentan facilitar que los indígenas controlen sus propios recursos culturales, ya que el Estado ha asumido el papel de administrar dichos asuntos y con ello ha usurpado la cultura y la historicidad indígenas. ${ }^{59}$

En1978, por partedel EstadosecreólaDirección GeneraldeEducaciónIndígena (DGEI) que sustituyó a la DGEEMI. Con su creación, las estrategias y medidas encaminadas a la formación docente se establecieron sobre "la incorporación y

55 Ibídem.

56 Ibídem, 195.

57 Ibídem, 198.

58 Ibídem, 202.

59 Ibídem, 205-206. 
participación de los propios indígenas en el proceso educativo". ${ }^{60} \mathrm{El}$ enfoque de los programas educativos para las pueblos originarios se determinó desde el modelo bicultural bilingüe como Educación Bicultural Bilingüe (EBB). Se pretendió formar a los promotores culturales bilingües en el campo académico, pedagógico y político ante la falta de formación docente. Para ello, un requisito era la primaria concluida; si se cumplía con este requisito, se les brindaba un curso preparatorio para el conocimiento y manejo de los programas y libros de texto, así como de técnicas pedagógicas para la enseñanza. ${ }^{61}$ Concluido esto, tenían la obligación de formarse como docentes indígenas dentro de los programas escolarizados o semiescolarizados que proporcionaba la Dirección General de Capacitación y Mejoramiento Profesional del Magisterio. Bertely ${ }^{62}$ señala que la Educación Bicultural Bilingüe continuó con el objetivo de integrar socioculturalmente a los grupos étnicos a la nación hegemónica a través de la revitalización de la lengua.

En 1978, se fundó en México la Universidad Pedagógica Nacional (UPN). La DGEI, ante la necesidad de profesionalización de promotores culturales, pretendía generar vínculos político-académicos con la UPN; sin embargo, en un inicio la UPN se opuso debido a su orientación ideológica institucional de tipo crítica, en el sentido de los objetivos de aculturación de los pueblos originarios por parte de la DGEI. No obstante, en 1982 la UPN firmó un convenio con la DGEI y desarrolló el programa de la Licenciatura en Educación Indígena, que tenía como objetivo "legitimar y consolidar cuadros profesionales indígenas, para que, desde el interior de los pueblos indios se generara el cambio políticoeducativo de acuerdo con la Educación Indígena Bilingüe Bicultural" ${ }^{63}$

No obstante, la iniciativa mostró algunas contradicciones debido a la poca coherencia entre los objetivos, el diseño curricular y las prácticas formativas, ya que se desarrolló sobre el diseño curricular general ya establecido para la formación de profesores mestizos, además de que tuvo un enfoque homogeneizante en lo correspondiente a la identidad cultural de los pueblos originarios. ${ }^{64} \mathrm{Al}$ mismo tiempo, desde abajo surgieron otros movimientos que se arraigaron en acciones de capacitación de maestros con el fin de reivindicar la educación en sintonía con los intereses de los pueblos originarios, como se vio en las Cañadas, Chiapas, a partir de 1988 por parte de la Asociación Regional de Interés Colectivo (ARIC), y en el pueblo Mixe de Oaxaca, con el dirigente Floriberto Díaz. ${ }^{65}$

En el caso de Colombia, 1971 fue un año referencial de los movimientos organizados por los pueblos originarios del Departamento del Cauca en la

\footnotetext{
60 Graciela Herrera Labra, "Los docentes indígenas. Breve historia", Reencuentro, 33 (2002): 34.

61 Ibídem.

62 María Bertely Busquets, "Educación indígena del siglo XX en México", en Un siglo de educación en México, tomo II, edr. Pablo Latapi Sarre (México: Consejo Nacional para la Cultura y las Artes/ Fondo de Cultura Económica, 1998), 87.

63 Graciela Herrera Labra, "Los docentes indígenas. Breve historia", Reencuentro, 33 (2002): 35.

64 Ibídem

65 Bruno Baronnet, Autonomía y educación indígena: las escuelas zapatistas de la Cañada de la Selva Lacandona, México (Tesis de Doctorado en Ciencia Social, Colegio de México y Université Sorbonne Nouvelle París III, 2009), 21.
} 
reivindicación de su lugar dentro de la sociedad en términos políticos, sociales y culturales -este Departamento es el territorio más densamente poblado por pueblos originarios en Colombia. ${ }^{66}$ Previo a ello se tiene conocimiento de movimientos de contrainsurgencia, como nos muestran Castillo y Caicedo ${ }^{67}$ a inicios de 1900, con la presencia de Manuel Quintín Lame en el Cauca, "un indígena educado que reivindicó los derechos sociales, sobre todo el derecho a la tierra, de los pueblos indígenas". ${ }^{68}$ Sin embargo, el movimiento de 1971 enmarcó el inicio de una organización que unió -y sigue uniendo- a varios pueblos originarios -nasa, misak, kokonukos y yanaconas- sobre demandas similares en torno a sus derechos políticos, específicamente en ese periodo, sobre los territorios de los cuales fueron despojados por los terratenientes. Este movimiento se concretó con la creación del Consejo Regional Indígena del Cauca -CRIC. Como señala Almario García, el movimiento se ha caracterizado por su rechazo a las relaciones de subordinación que dejaban a los pueblos originarios en desventaja económica, cultural, política y social frente a la hegemonía ${ }^{69}$

Considero importante exponer las condiciones en que surgió el CRIC, en razón de ser referente principal en la construcción de la identidad de los pueblos originarios de la región. Al surgimiento del CRIC le anteceden un conjunto de relaciones que datan desde el siglo XVIII entre distintos grupos sociales con los pueblos originarios de la zona -principalmente los terratenientes, quienes tenían vínculos con los Cabildos-, lo cual generó desventaja sobre sus tierras a estos últimos. ${ }^{70}$ Los pueblos originarios se organizaron primariamente en torno a la recuperación del territorio que ancestralmente les pertenecía. En este camino se mezclaron dos vertientes sociales que dieron fuerza al movimiento social: la organización comunitaria con sus respectivas dificultades, y el asesoramiento de agentes políticos externos quienes pusieron a disposición de los pueblos originarios sus conocimientos y elementos conceptuales. ${ }^{71}$

Antes de la creación del CRIC, los pueblos originarios crearon en 1962 el Sindicato Gremial Agrario, que más adelante se transformó en la Cooperativa Agraria de las Delicias, con intención de obtener un préstamo para la compra de la Finca San Fernando, acción que tenía como fin recuperar las tierras de sus antepasados. ${ }^{72}$ En este sentido, a finales de la década de 1960 e inicios de 1970

66 Oscar Almario García, Ensayo 2 "La etnohistoria de los Andes del Sur de Colombia y las tierras bajas adyacentes del Amazonas y del Pacífico", en La invención del suroccidente colombiano, eds. José Olimpo Suárez Molano y Carlos Alberto Patiño Villa (Medellín: Universidad Pontificia Bolivariana, 2005), 60.

67 Elizabeth Castillo y José Antonio Caicedo, La educación intercultural bilingüe: el caso colombiano (Buenos Aires: Fund. Laboratorio de Políticas Públicas, 2009), 18.

68 Carlos Medina Betancur, "La autonomía educativa indígena en Colombia”, Vniversitas, 124 (2012): 280.

69 Oscar Almario García, Ensayo 2 "La etnohistoria de los Andes del Sur de Colombia y las tierras bajas adyacentes del Amazonas y del Pacífico", en La invención del suroccidente colombiano, eds. José Olimpo Suárez Molano y Carlos Alberto Patiño Villa (Medellín: Universidad Pontificia Bolivariana, 2005), 60.

70 Ibídem, 54.

71 Daniel Ricardo Peñaranda, Capítulo I: "La organización como expresión de resistencia”, en Nuestra vida ha sido nuestra lucha, eda. Beatriz Acevedo (Bogotá: Taurus, Semana, Centro de Memoria Histórica, 2012), 23.

72 Ibídem, 39 
(...) la movilización [de los pueblos originarios del Departamento del Cauca,] (...) tuvo como principales objetivos la recuperación de las tierras comunales y un proceso de reconstrucción identitaria, a través del fortalecimiento de las autoridades tradicionales y la recuperación de valiosos rasgos culturales, como la lengua, apoyándose para todo ello en la reinvención de la tradición histórica. ${ }^{73}$

Con el apoyo y orientación de diferentes agentes externos, principalmente algunos que laboraban en el Instituto Colombiano de la Reforma Agraria (INCORA), se creó el CRIC con el fin de alcanzar la autonomía territorial con base en la organización campesina. ${ }^{74}$ En el acta constitutiva del seis de septiembre de 1971, denominada "Plataforma de lucha", el CRIC determinó siete líneas ${ }^{75}$ sobre las cuales encaminaría sus acciones; una de ellas, orientada a la educación:

La revalorización, conformación y desarrollo de proyectos educativos, que correspondan a los intereses, realidad sociocultural, necesidades y expectativas de las comunidades. Implica la formación de maestros bilingües y, en general, la formación de todos y cada uno de los miembros de las comunidades de acuerdo a sus funciones $y$ a los requerimientos de la modernidad. ${ }^{76}$

La organización política de los pueblos originarios que dieron vida al CRIC emergió en un entramado de complejas relaciones entre los distintos grupos sociales de la región en torno a las disputas por el territorio. ${ }^{77}$ De este modo, se combinaron: la expansión de las haciendas en los resguardos ${ }^{78}$ de los pueblos originarios, el asentamiento de colonos en los resguardos, las acciones del Ejército en el oriente contra los grupos insurgentes -que también amenazaron a los pueblos originarios-, la inseguridad causada por los bandoleros y exguerrilleros, las acciones de la Reforma Agraria, y la expansión de la industria azucarera. ${ }^{79}$ Todo esto culminó con la expulsión de la población campesina del territorio, principalmente población conformada por los pueblos originarios y afrodescendientes. ${ }^{80}$

Sin embargo, las tensiones sociales, que en muchos momentos generaron reacciones violentas, no disminuyeron con la fundación del CRIC. La ubicación

\footnotetext{
73 Ibídem, 21.

74 Ibídem, 27

75 Consejo Regional Indígena del Cauca, Caminando la palabra. Congresos del Consejo Regional Indígena del Cauca, eda. Graciela Bolaños (Popayán: PEBI-CRIC, 2011), 17.

76 Carolina Hirmas, et al., Políticas educativas de atención a la diversidad cultural: Brasil, Chile, Colombia, México y Perú (Santiago: OREALC/UNESCO, 2005), 288.

77 Daniel Ricardo Peñaranda, Capítulo I: “La organización como expresión de resistencia”, en Nuestra vida ha sido nuestra lucha, eda. Beatríz Acevedo (D.C.Bogotá: Taurus, Semana, Centro de Memoria Histórica, 2012), 22.

78 “Tanto la resistencia como la ambigua situación que producía el uso de la tierra y la carencia de la mano de obra para la producción, hizo que el Rey Felipe II, 1551 decretara reordenar y fijar las posesiones de tierras, no solo de los encomenderos sino también de los indígenas. A estas posesiones (...) se les llamó RESGUARDOS”. Consejo Regional Indígena del Cauca, Legislación Indígena (D.C. Bogotá: CRIC/ PEBI: 2014), 17.

79 Consejo Regional Indígena del Cauca, Historia del CRIC (Popayán: CRIC Programa de Capacitación, Junio de 1990), 13.

80 Ibídem.
} 
geográfica y topográfica del Departamento del Cauca facilitó la llegada de actores armados de varias latitudes con diversos intereses políticos. Esta realidad exigió a los pueblos originarios, a través del CRIC, la creación de un grupo de autodefensa -Movimiento Armado Quintín Lame ${ }^{81}$, , por medio del cual se enfrentaron violenta y políticamente a los actores armados e hicieron llamados al Estado. Dentro de los grupos armados a quienes tuvieron que hacer frente se encontraron diferentes divisiones de las Fuerzas Armadas de Colombia (FARC), el Ejército Popular de Liberación (EPL), el Ejército de Liberación Nacional (ELN), los paramilitares y las Autodefensas Unidas de Colombia (AUC) -asociados con el narcotráfico. ${ }^{82}$ El Movimiento 19 de abril (M19) apoyó a la organización de autodefensas de los pueblos originarios; sin embargo, su presencia en el Departamento del Cauca puso en riesgo a los pueblos originarios al ser perseguidos por el Estado.

Fue así que la lucha por el territorio consistió en una reivindicación no solamente ante el Estado, sino ante distintos grupos sociales que pugnaban por la primacía social, económica, política y territorial. Esta concepción del territorio se complementó con otra relacionada con la cultura: al significar el territorio un espacio de memoria colectiva. ${ }^{83}$ Ante estas experiencias de desventaja histórica, el CRIC concibió a la educación como un proyecto político que se articularía con la lucha por la tierra, la cultura, la unidad y la autonomía; por lo cual, planteó los inicios de la Educación Propia -término que comienzan a utilizar los pueblos originarios a inicios de la década de 1990, sustituyendo el de Etnoeducación, al ser este último propuesta del Estado y considerarlo distante de los objetivos sobre el fortalecimiento de su identidad cultural.

El interés inicial de los pueblos originarios y del CRIC, una vez consolidado, en la capacitación política para la recuperación de las tierras, culminó con la creación de escuelas comunitarias, con el fin de integrar en la educación "la memoria y la vida de los pueblos" en la revitalización de las identidades colectivas de los pueblos originarios. ${ }^{84}$ Frente a una

(...) educación oficial [que] se caracterizaba por el divorcio entre la escuela y la política comunitaria, por la no valoración de lo indígena, la ausencia de respeto por las autoridades comunitarias, el autoritarismo de los maestros y, una enseñanza que desconocía y menospreciaba el entorno del estudiante (...), implementada por medio de la escuela (...) [la cual era] percibida [por los pueblos originarios] como una institución ajena a su estructura cultural y social (...) $)^{85}$,

81 Gobierno Nacional, Acuerdo Final entre el Gobierno Nacional y el Movimiento Armado Quintín Lame, eds. Amparo Díaz y Darío Villamizar (D.C. Bogotá: Quebecos Impreandes, 1999), 53.

82 Daniel Ricardo Peñaranda, Capítulo V: "Las guerras de los años ochenta y la resistencia contra los actores armados", en Nuestra vida ha sido nuestra lucha, eda. Beatriz Acevedo (D.C. Bogotá: Taurus, Semana, Centro de Memoria Histórica, 2012), 173-181.

83 Graciela Bolaños, Capítulo VII: "Motivando la memoria para reconstruir la historia educativa indígena de los pueblos del Cauca", en Nuestra vida ha sido nuestra lucha, eda. Beatríz Acevedo (D.C.Bogotá: Taurus, Semana, Centro de Memoria Histórica, 2012), 243.

84 Ibídem, 254.

85 Ibídem, 255. 
emergió la propuesta del CRIC, en 1978, con el Programa de Educación Bilingüe (PEB). El objetivo de la creación de este programa fue "investigar una propuesta educativa indígena como base de la búsqueda de autonomía". ${ }^{86}$ Asimismo, el PEB tuvo a su cargo la formación docente y el seguimiento de las escuelas comunitarias. De modo que después de la organización política para la recuperación de la tierra, los pueblos originarios del Cauca notaron la necesidad de continuar con el fortalecimiento de la comunidad en términos políticos; el camino fue la construcción de escuelas comunitarias. El principal eje articulador de la escuela resultó ser el político antes que el pedagógico. ${ }^{87}$

Así, dentro del CRIC, la educación se rige sobre tres ejes: la tierra, las lenguas y el pensamiento del pueblo originario, y la autonomía. ${ }^{88}$ Bolaños ${ }^{89}$ distingue que la construcción de la educación propia se vio fortalecida por dos estrategias: a) la selección de los maestros y maestras bilingües, y b) el papel del cabildo como mecanismo de autoridad propia y de participación. La primera estrategia, que es la que en estos momentos nos atañe, corresponde a la formación docente, para lo cual, en un inicio, la comunidad a través de los cabildos, eligió a las personas que fungían como dirigentes locales, quienes generaban confianza y respeto dentro de la comunidad. Se pretendía que fueran personas con acción política porque los maestros, dentro del CRIC, son agentes políticos para el cambio político y educativo a favor de las propias identidades culturales. ${ }^{90}$

El CRIC no abandonó la profesionalización de los y las docentes. Por el contrario, la profesionalización de las personas elegidas para llevar el cargo implicó relación con toda la comunidad, a diferencia de los modelos educativos del Estado. La finalidad de la formación docente era el fortalecimiento de la comunidad en general, no solo en términos pedagógicos; por lo cual, la formación era contextualizada dependiendo de las necesidades de la comunidad misma. Así, el maestro se construía colectivamente; la comunidad era la principal fuente de formación por medio de las asambleas, reuniones, talleres, juntas y otras acciones comunitarias donde se valoraba el trabajo realizado hasta el momento y se hacían críticas hacia la acción pedagógica en torno a lo político, productivo, social y cultural. ${ }^{91}$ Frente al proceso individualista de la educación estatal, se encontraba el proceso colectivista de la educación propia.

A la par de la creación de las escuelas comunitarias, seguían los procesos de profesionalización docente para el grado básico. En las reuniones comunitarias se recreaba la historia propia, se revitalizaba la lengua y la cultura ${ }^{92}$, se generaba

\footnotetext{
86 Graciela Bolaños y Abelardo Ramos, ¿Qué pasaría si la escuela? 30 años de construcción de una educación propia (Popayán: CRIC, Fuego Azul, 2004), 39.

87 Ibídem, 37.

88 Graciela Bolaños, Capítulo VII: "Motivando la memoria para reconstruir la historia educativa indígena de los pueblos del Cauca", en Nuestra vida ha sido nuestra lucha, eda. Beatriz Acevedo (D.C. Bogotá: Taurus, Semana, Centro de Memoria Histórica, 2012 ), 247.

89 Ibídem, 260.

90 Graciela Bolaños y Abelardo Ramos, ¿Qué pasaría si la escuela? 30 años de construcción de una educación propia (Popayán: CRIC, Fuego Azul, 2004), 39.

91 Ibídem, 45.

92 Consejo Regional Indígena del Cauca, Encuentro regional de mayores y mayoras para el fortalecimiento de los saberes ancestrales de
} 
todo lo que sería llevado a la educación con los niños y niñas, y se hacía con ayuda de gente externa a los territorios, como educadores, psicólogos y antropólogos. ${ }^{93}$ En este sentido, la metodología utilizada en todo el proceso fue la investigación acción para la reconstrucción social y cultural, que constituyó la estrategia central del Programa en Educación Bilingüe. ${ }^{94}$ El proceso no fue homogéneo en todo el territorio del Cauca, ni los fines fueron siempre los mismos. Los iniciadores fueron los nasa, sin embargo, se unieron al movimiento otros pueblos originarios como los misak, que más adelante se separarían. Las finalidades versaban sobre la cultura, el territorio y la organización política, en cada sitio con matices y prioridades distintos. Hubo territorios donde se crearon escuelas comunitarias que después desaparecieron porque no hubo arraigo dentro de la comunidad, como el caso de la escuela Miravalle en el municipio de Suárez. ${ }^{95}$

Más adelante, la profesionalización de maestros y maestras indígenas tomó orientaciones distintas en algunos intentos por generar procesos de formación en conjunto con el Estado, posterior al Decreto 1142 de $1978 .{ }^{96}$ Estas acciones conjuntas guiaron la formación de bachilleres pedagógicos con énfasis en etnoeducación dentro de los resguardos de los pueblos originarios; y en un acto de autonomía por parte de los pueblos originarios del Cauca, a inicios de la década del 2000, se creó la profesionalización a nivel universitario dentro de la Universidad Autónoma Indígena Intercultural -UAIIN-. ${ }^{97}$

Podemos notar así que son intereses prioritarios de los pueblos originarios del Cauca tanto la identidad como la educación en relación con la recuperación política, cultural y territorial, en un sentido diferente al que venían realizando, desde la imposición de la cultura occidental y el desarraigo de sus propias formas organizativas y culturales, el Estado y la Iglesia-docente, a través de los procesos educativos de castellanización, monolingüismo y asimilación.

$\mathrm{Al}$ movimiento del CRIC le siguieron otros dentro del territorio colombiano que a su vez se retroalimentaron de distintas experiencias que ocurrían en el territorio de América Latina y del conocimiento de casos similares de exclusión social y política a través de los congresos y reuniones internacionales. Dentro del movimiento social de los pueblos originarios de Colombia surgieron otras organizaciones como el Consejo Regional Indígena de Tolima (CRIT) en 1975, el Consejo Regional Indígena del Vaupés (CRIVA) y la Organización Nacional Indígena de Colombia (ONIC) en 1982. ${ }^{98} \mathrm{Al}$ año 2005, como hace referencia Hevia, las organizaciones pertenecientes a la ONIC eran un poco más de 30, y

los pueblos originarios (Popayán: CRIC, 2014), 2.

93 Ibídem, 46, 51.

94 Ibídem, 52.

95 Ibídem, 45 .

96 Presidente de la República de Colombia, Decreto 1142 de 1978 (Colombia: Diario Oficial de la Federación, 10 de julio de 1978 ), 1.

97 Ibídem, 174.

98 Carolina Hirmas, et al., Politicas educativas de atención a la diversidad cultural: Brasil, Chile, Colombia, México y Perú (Santiago: OREALC/UNESCO, 2005), 288. 
sus demandas o ejes de acción continuaban orientándose hacia su autonomía y su cultura tradicional, incluida la institución educativa.

Por su parte, el Estado colombiano, ante las exigencias de los pueblos originarios y los movimientos de contrainsurgencia que ocurrían a nivel internacional, sobre todo en el territorio de América Latina, reformó el Concordato que firmó con la Iglesia en 1887, a través de la Ley 20 de 1974, con lo que culminó el monopolio de esta institución sobre la educación para los pueblos originarios. Sin embargo, el Estado se vio en la necesidad de contratar a la Iglesia como educadora debido a que, nuevamente, no contaba con los medios necesarios para atender la educación de los pueblos originarios. ${ }^{99}$

En 1978, ante los proyectos iniciados por el CRIC en educación básica y formación docente, y la insistencia de nombramientos de docentes indígenas bilingües por parte de los pueblos originarios, el Estado colombiano, a través del Decreto 1142, consideró por primera vez el derecho de los pueblos originarios a una educación diferente con el fin de preservar y divulgar las culturas autóctonas de la región, con lo cual comenzó a hablar de educación para los pueblos originarios con un enfoque bicultural y bilingüe. ${ }^{100}$ Los principales puntos establecidos en tal Decreto fueron la aprobación de proyectos educativos acordes a las características culturales de cada pueblo originario, el derecho de los pueblos originarios a participar en el diseño de los programas educativos, la alfabetización en lengua materna y la definición de criterios para la selección del profesorado indígena, entre los que se encontraban que fueran bilingües y pertenecientes al pueblo originario al que impartirían clase. Así, el Ministerio de Educación Nacional lanzó la política de profesionalizar a todos los maestros urbanos y rurales en etnoeducación. ${ }^{101}$

Aun cuando la iniciativa de etnoeducación mostró sus inicios en 1978, fue hasta 1984 que se institucionalizó al enfoque por parte del MEN en todo el territorio colombiano, a través de la creación del Grupo de Etnoeducación para la formación docente. ${ }^{102}$ La educación bicultural y bilingüe en los grados básicos fue proporcionada por la Iglesia -como educación contratada- y otras organizaciones educativas, pero seguía los mismos lineamientos de la educación convencional. En 1985, el MEN creó el Programa de Etnoeducación.

A través del artículo primero del Decreto 085, creado en $1980^{103}$, el Estado señaló que el requisito esencial para nombrar docentes en educación para los pueblos originarios era que fueran bilingües y no el mínimo de escolaridad. ${ }^{104}$ El Decreto 2762 de $1980^{105}$ establece que el MEN organizará un sistema de

\footnotetext{
99 Carlos Medina Betancur, "La autonomía educativa indígena en Colombia", Vniversitas, 124 (2012): 278.

100 Ibídem, 281.

101 Graciela Bolaños y Abelardo Ramos, ¿Qué pasaría si la escuela? 30 años de construcción de una educación propia (Popayán: CRIC, Fuego Azul, 2004), 62.

102 Ibídem.

103 Presidente de la República de Colombia, Decreto Número 85 de 1980 (Bogotá: Diario Oficial, 27 de febrero de 1980), 1.

104 Elizabeth Castillo y José Antonio Caicedo, La educación intercultural bilingüe: el caso colombiano (Buenos Aires: Fund. Laboratorio de Políticas Públicas, 2009), 23.

105 Presidente de la República de Colombia, Decreto 2762 de 1980 (Bogotá: Diario Oficial, 31 de octubre de 1980), 1.
} 
profesionalización especial para docentes indígenas que laboren en las comunidades. ${ }^{106}$ Ante esta situación, de 1986 a 1995, conforme a lo dicho en la resolución 9549 de 1986, y acorde con el Programa de Etnoeducación, el MEN estableció y autorizó un sistema de profesionalización para maestros indígenas a través de los Centros Experimentales Piloto (CEP) que ya venían adelantando acciones de formación docente en educación regular y en pueblos originarios, con base en el Decreto $088^{107}$ de $1976 .{ }^{108}$ Los CEP fueron las instancias del MEN encargadas de coordinar el Programa de Etnoeducación en las regiones, orientado a la capacitación como bachilleres pedagógicos a docentes indígenas que ya se encontraban en labor sin previa formación formal. ${ }^{109}$ Fue así que se contrató a capacitadores pertenecientes a distintos ámbitos de la investigación -fundaciones, organizaciones indígenas, escuelas normales, universidadespara organizar los seminarios de capacitación docente, los cuales consistían en nivelar, profesionalizar y actualizar al profesorado indígena. En este sentido, y en relación con las demandas del CRIC sobre el control de los procesos de formación docente,

El Ministerio de Educación Nacional de Colombia (MEN) resolvió implementar la educación indígena con el nombramiento de maestros indígenas bilingües, la creación del Grupo de Etnoeducación del MEN, el reconocimiento del Comité Nacional Lingüística Aborigen y la aceptación y autorización de un programa especial de profesionalización de maestros indígenas, entre otros. (...) el Estado pactó con las organizaciones indígenas el desarrollo de la "etnoeducación". (...) el CRIC decidió participar en la profesionalización de maestros, abriendo su programa a otros sectores de la población indígena caucana. (...) Se debatió intensamente en los cabildos y en las comunidades que tenían escuelas, al igual que en el nivel central del CRIC, las implicaciones de trabajar conjuntamente con el Estado el proceso de profesionalización. Se concluyó que se trabajaría una propuesta elaborada por el PEB, basada en las experiencias educativas en curso, y que el Estado se encargaría de financiarla. ${ }^{110}$

Aun cuando el Estado aceptó la propuesta del CRIC en 1987 sobre financiar el proyecto que la organización lideraba, fue hasta dos años después de su inicio -1988- que aportó el financiamiento. Mientras tanto, el CRIC recibió apoyo económico del Instituto Colombiano de Reforma Agraria (INCORA), para después tener una cofinanciación con el MEN para las cuatro promociones posteriores. El CRIC, junto con su Programa de Educación Bilingüe, fueron los encargados de coordinar el desarrollo académico y logístico del proyecto de profesionalización. ${ }^{111}$ Así, a la par de las propuestas del Estado desde las

\footnotetext{
106 Ibídem.

107 Presidente de la República de Colombia, Decreto 088 de 1976 (Bogotá: Diario Oficial, febrero de 1976), 1.

108 Graciela Bolaños y Abelardo Ramos, ¿Qué pasaría si la escuela? 30 años de construcción de una educación propia (Popayán: CRIC, Fuego Azul, 2004), 222.

109 Ibídem.

110 Ibídem, 68-69.

111 Ibídem, 63.
} 
escuelas normales, se encontraba en marcha la propuesta de bachiller con énfasis en etnoeducación por una de las escuelas normales en convenio con el CRIC y la Secretaría de Educación del Cauca desde 1988, resultado del acuerdo entre el CRIC y el Estado. ${ }^{112}$ Casi todos los maestros participantes se encontraban en ejercicio docente. Durante la formación de los bachilleres siguió siendo importante la investigación, por lo cual se llevaron a cabo los proyectos pedagógicos en relación con las necesidades y demandas de la comunidad, no sólo en el ámbito educativo. ${ }^{113}$

Conforme a lo expuesto, es posible notar que la educación, desde los pueblos originarios, es concebida como un espacio para la reivindicación de la identidad sociocultural que permite la transformación de la sociedad, la mentalidad y la conciencia étnica. Bajo esta concepción y significado de la educación,

(...) los movimientos indígenas en América Latina colocan en el centro de sus reivindicaciones la necesidad de revitalizar las lenguas y culturas propias, pero también la de forjar conciencias étnicas y políticas, influyendo sobre la redefinición de contenidos y métodos pedagógicos permeados por los valores hegemónicos. El mecanismo principal del sistema de escolarización está representado por el docente, que se atribuye la responsabilidad de asumir la ejecución de un programa pedagógico específico, haciendo respetar ciertas reglas socialmente aceptadas por las autoridades educativas. ${ }^{114}$

Sin embargo, los Estados nacionales homogéneos continuaron con el planteamiento de propuestas que seguían sin considerar por completo las distintas identidades culturales presentes en el territorio nacional, como la educación bicultural y bilingüe.

\section{CONCLUSIÓN}

La comparación entre México y Colombia en torno a la historia sociopolítica de la educación indígena y la emergencia de identidades del profesorado indígena, se basó en la similitud entre los procesos de ambas regiones: una historia de negación de la nación plural con gran presencia de pueblos originarios; la conformación de un Estado nacional homogéneo posterior a la Colonia a través de la educación oficial; luchas por y desde los pueblos originarios por el reconocimiento y validación de sus identidades diferenciadas aunadas a la exigencia de una educación acorde con su heterogeneidad. Un contexto donde es reconocida la importancia de la identidad del profesorado indígena en el campo sociopolítico.

\footnotetext{
112 Ibídem, 69.

113 Ibídem, 75 .

114 Bruno Baronnet, Autonomía y educación indígena: las escuelas zapatistas de la Cañada de la Selva Lacandona, México. (Tesis de Doctorado en Ciencia Social, Colegio de México y Université Sorbonne Nouvelle París III, 2009), 24.
} 
Planteé, en un primer momento, un breve recorrido sobre los orígenes de la educación indígena y la formación docente en México y Colombia, de la colonia a la constitución republicana, donde el objetivo que tiñó a la educación -sea en México bajo la dirección del Estado, o en Colombia por la relación entre la Iglesia y el Estado- fue la asimilación de las identidades diferenciadas; es decir, la aculturación y la asimilación a una identidad nacional. Esta asimilación pretendió acabar con "el problema indígena". ${ }^{115}$ En un segundo momento acentué, en ambos casos, el periodo de levantamientos contrainsurgentes de los pueblos originarios en la lucha por sus derechos colectivos, de tierra y cultura -aunque más fuertemente en Colombia por la posibilidad de organización política-, de donde surgieron propuestas educativas desde "abajo" y un nuevo planteamiento de la educación que el Estado ofreció a los pueblos originarios, el cual comenzó a aludir a lo intercultural bilingüe. En varias regiones de América Latina, incluidas México y Colombia, este reconocimiento se acompañó -y acompaña- de fuertes luchas físicas e ideológicas manifiestas en el campo educativo que nacieron desde abajo, con un sentido profundo de reivindicación étnica, cultural, política y social, que tienen en su origen un largo pasado de relaciones asimétricas y de desigualdad social, territorial, cultural y económica, basadas en la idea de etnicidad y raza, como refieren López ${ }^{116}$ y Villoro ${ }^{117}$.

Es en ese punto de tensión donde los movimientos sociales, como los que emergen de los pueblos originarios, encuentran espacios para correr en el continuo de empoderamiento y logro de derechos, "y es aquí donde la incautación de las fisuras y rupturas, las contradicciones en los programas, las políticas, las instituciones y los discursos de "el estado" permiten a la gente crear posibilidades para la acción política y el activismo". ${ }^{118}$ Las políticas mismas son manifestaciones de estas tensiones, ya que "toda política pública, aunque forme parte de un proyecto de dominación, refleja, como arena de lucha y como caja de resonancia de la sociedad civil, tensiones, contradicciones, acuerdos y desacuerdos políticos, a veces de gran magnitud" ${ }^{119}$ En ello, es posible distinguir que el Estado mantiene una postura pasiva ante la diversidad de realidades complejas y desventajosas que viven los grupos sociales ${ }^{120}$, en una exclusión incluyente. ${ }^{121}$ En este tenor, son los movimientos de los pueblos originarios de Colombia y México quienes presionan desde abajo para que ocurran cambios

115 Ibídem, 92.

116 Néstor López, La educación de los pueblos indígenas y afrodescendientes. Informe sobre tendencias sociales y educativas en América Latina 2011 (Buenos Aires: Instituto Internacional de Planteamiento de la Educación IIPE-UNESCO, 2011 ), 29.

117 Luis Villoro, Tres retos de la sociedad por venir: justicia, democracia, pluralidad, (México: Siglo XXI, 2009 ), 22.

118 Akhil Gupta, "Fronteras borrosas: el discurso de la corrupción, la cultura de la política y el estado imaginado". En Antropología del Estado, eds. Aradhana Sharma y Akhil Gupta (México: Fondo de Cultura Económica, 2015), 133.

119 Carlos Torres, "Estado, privatización y política educacional. Elementos para una crítica del neoliberalismo", en Pedagogía de la exclusión. Crítica al neoliberalismo en educación, eds. Juan Antonio Rosado y Marcela Solís Quiroga (México: UACM, 2004$), 163$.

120 Consejo Regional Indígena del Cauca, Sistema Educativo Indígena Propio. Primer documento de trabajo (Popayán: CRIC, PEBI, 2011), 26.

121 Pablo Gentili, Pedagogía de la igualdad. Ensayos contra la educación excluyente (Buenos Aires: Siglo XXI Editores-Clacso, 2011 ), 108. 
en el nivel legislativo estatal, en las demandas sobre el reconocimiento de sus identidades diferenciadas para el ejercicio político.

De modo que, en la continuidad de ambos momentos, presenciamos contraposición en términos políticos, por un lado, del Estado -en México- o la Iglesia en relación con el Estado -en el caso de Colombia hasta 1991-, en la imposición de políticas educativas y de identidad que nulificaban a los pueblos originarios; y, por otro lado, la resistencia y lucha de los pueblos originarios para su visibilidad dentro del mismo ámbito, pero con un antecedente de movimiento político, cultural y territorial. Es decir, distinguimos las tensiones entre la estructura de los grupos hegemónicos y la agencia de los pueblos originarios; entre la imposición de una ciudadanía individual y la acción de una identidad colectiva; entre la práctica colonizadora y la descolonización; todo lo cual discurre en tejidos o redes del poder relacional.

En esta relación dominada por tensiones entre el Estado y los pueblos originarios, emerge la identidad del profesorado indígena como sujeto con capacidad de agencia política en el campo de la educación para/por los pueblos originarios -reitero, para los fines políticos del Estado o de los pueblos originarios-. Sin embargo, la identidad que surge no refiere a una identidad homogénea, sino a identidades plurales, que lejos de gestarse como estáticas ${ }^{122}$ o "líquidas"123, se encuentran en constante construcción a través de los procesos de formación y profesionalización -práctica- que se gestan en este periodo conforme a las luchas políticas -físicas e ideológicas- entre el Estado y los pueblos originarios, lo cual, refiere distintos frentes desde los cuales se nutren. Es una identidad que se mueve por los procesos de lucha y que, a su vez, moviliza a estos. Las referencias que aquí se hicieron, mostraron identidades de reivindicación cultural. Así, la educación, lejos de ser un espacio armónico y neutral, representa un espacio de tensiones políticas y sociales, donde se han expuesto los temas de la consolidación nacional y, como eje paralelo, el desarrollo económico que se enlaza con los ámbitos cultural y social. Específicamente, esto puede notarse en la búsqueda de un perfil de ciudadanía acorde con los valores occidentales liberales de privatización de la tierra, de ingreso a un mercado nacional, del individualismo sobre la colectividad. ${ }^{124}$ En esta envergadura, la formación docente adquiere un carácter politizado, al fungir el profesorado un rol de intermediario entre los intereses de los grupos dirigentes -sean los pueblos originarios o los representantes del Estado- y la población de los pueblos originarios a quienes se pretende acercar una educación sostenida de una ideología específica y representativa. La identidad del profesorado indígena es una identidad política.

En todo esto, el papel del profesorado indígena ha ocupado un lugar de relevancia en los distintos proyectos educativos de ambas regiones. Esta relevancia se muestra en el discurso político desde 1970 por parte de los pueblos

122 Guillermo Bonfil Batalla, México profundo (México: CONACULTA, 1990).

123 Zigmunt Bauman, Identidad (Buenos Aires: Losada, 2005).

124 Aníbal Quijano, "El “movimiento indígena” y las cuestiones pendientes en América Latina”, Argumentos, 50 (2006): 59. 
originarios del Cauca, Colombia, donde hicieron explícita la necesidad de elegir a sus maestros y maestras, dentro de las distintas reuniones y congresos locales, nacionales e internacionales, y por la constante posición del Estado en ambas regiones de liderar tales procesos. El hecho es evidente a través de las leyes y reformas educativas del Estado, en las cuales comenzó a aparecer en pugna la decisión autónoma de elegir a los y las docentes. A su vez, esto se manifiesta en los intereses políticos por parte de los Estados de México y Colombia, al no ceder por completo la autonomía de los pueblos originarios en lo concerniente a la formación de su profesorado. En los años siguientes, relaciones similares generarán tensiones en el territorio mexicano por parte de los pueblos originarios del sureste mexicano, en la práctica de movilizar la línea divisoria "dominación/subordinación" hacia la presencia activa de los pueblos originarios en la emergencia y cambios de las identidades culturales.

Conforme a lo anterior, y de cerca al posicionamiento teórico de Giménez ${ }^{125}$, se concibe que los procesos históricos en la educación de los pueblos originarios forman parte del contexto político macrosocial, a través del cual el profesorado indígena construye su identidad. Específicamente, se considera que este contexto incide en la memoria colectiva y en la movilización social de los pueblos originarios que sigue presente en generaciones posteriores, rebasando las fronteras del presente, para las luchas sobre el posicionamiento reivindicador de sus propias identidades culturales. El profesorado indígena aparece, en los casos analizados, como un colectivo con capacidad de agencia que se moviliza conforme a las luchas -a la vez que las moviliza- del colectivo más amplio: la comunidad. Lo anterior, abre la brecha para una línea de investigación que debe seguir profundizándose, en el sentido que las tensiones entre los Estados y los pueblos originarios -y otros grupos sociales-, en el contexto de las nuevas relaciones propiciadas por la economía neoliberal, generan una permanente dinámica de lucha y reivindicación a través de las relaciones de poder emergentes.

\section{FUENTES}

Almario García, Oscar. Ensayo 2 "La etnohistoria de los Andes del Sur de Colombia y las tierras bajas adyacentes del Amazonas y del Pacífico". En La invención del suroccidente colombiano, editado por José Olimpo Suárez Molano y Carlos Alberto Patiño Villa. Medellín: Universidad Pontificia Bolivariana, 2005, 43120.

Assies, Willem, et al. "Los pueblos indígenas y la reforma del Estado en América Latina". Papeles de Población, 31 (2002): 95-115.

125 Gilberto Giménez, Identidades Sociales (México: Consejo Nacional para la Cultura y las Artes, Instituto Mexiquense de Cultura, 2009), 54-59. 
Baronnet, Bruno. "Autonomía y educación indígena: las escuelas zapatistas de la Cañada de la Selva Lacandona, México". Tesis de Doctorado en Ciencia Social, Colegio de México y Université Sorbonne Nouvelle París III, 2009.

Baronnet, Bruno. y Medardo Tapia Uribe. “Introducción: política, educación e interculturalidad". En Educación e interculturalidad: política y políticas, editado por Margarita Velázquez Gutiérrez, Blanca Rebeca Ramírez Velázquez, Antonio García de León Griego, Elsa María Cross y Anzaldúa y Carlos Javier Echarri Cánovas. México: CRIM, 2013, 9-21.

Bartolomé, Miguel Alberto, Guillermo Bonfil, Víctor Daniel Bonilla, Gonzalo Castillo, Miguel Chase-Sardi, Georg Grünberg, Nelly Arvelo, Esteban Mosonyi, Darcy Ribeiro, Scott Robinson y Stefano Varese. Declaración de Barbados. 1971. http://www.libertadciudadana.org/archivos/Biblioteca\%20Virtual/ Documentos\%20Informes\%20Indigenas/Documentos\%20Internacionales/ Declaracion \%20de\%201os\%20Pueblos\%20Indigenas/Declaracion $\% 20$ Barbados\%201971.pdf (12 de febrero, 2016).

Bauman, Zygmunt. Identidad. Buenos Aires: Losada, 2005.

Bello Domínguez, Juan. "El inicio de la educación bilingüe bicultural en las regiones indígenas en México". En Memoria electrónica del X Congreso Nacional de Investigación Educativa COMIE, línea temática 9: Historia e historiografía de la Educación. Editado por Susana Quintanilla Osorio y María Candelaria Valdés Silva. Veracruz, México, 2009, 1-10.

Bertely Busquets, María. "Educación indígena del siglo XX en México". En Un siglo de educación en México, tomo II. Editado por Pablo Latapi Sarre. México: Consejo Nacional para la Cultura y las Artes/ Fondo de Cultura Económica, 1998, 74-110.

Bloch, Marc. "A favor de una historia comparada de las civilizaciones europeas". En Historia e historiadores. Traducido por Francisco González García. Madrid: Akal, 1999, 113-147.

Bolaños, Graciela y Abelardo Ramos. ¿Qué pasaría si la escuela? 30 años de construcción de una educación propia. Popayán: CRIC, Fuego Azul, 2004.

Bolaños, Graciela, Capítulo VII: "Motivando la memoria para reconstruir la historia educativa indígena de los pueblos del Cauca". En Nuestra vida ha sido nuestra lucha. Editado por Beatriz Acevedo. Bogotá: Taurus, Semana, Centro de Memoria Histórica, 2012, 235-274.

Bonfil Batalla, Guillermo, Esteban Emilio Mosonyi, Gonzalo Aguirre Beltrán, Lourdes Arizpe y Silvia Gómez Tagle. “La declaración de Barbados II y comentarios". Nueva Antropología II, diciembre (1977): 109-125.

Bonfil Batalla, Guillermo Guillermo. México profundo. México: CONACULTA, 1990.

Cardoso de Oliveira, Roberto. Etnicidad y estructura social. México: CIESAS, UAM, Universidad Iberoamericana, 2007.

Castillo, Elizabeth y José Antonio Caicedo. La educación intercultural bilingüe: el caso colombiano. Buenos Aires: Fund. Laboratorio de Políticas Públicas, 2009.

Consejo Regional Indígena del Cauca. Historia del CRIC. Popayán: CRIC Programa de Capacitación, junio de 1990. 
Consejo Regional Indígena del Cauca. Sistema Educativo Indígena Propio. Primer documento de trabajo. Popayán: CRIC, PEBI, 2011.

Consejo Regional Indígena del Cauca. Caminando la palabra. Congresos del Consejo Regional Indígena del Cauca. Editado por Graciela Bolaños. Popayán: PEBICRIC, 2011.

Consejo Regional Indígena del Cauca. Encuentro regional de mayores y mayoras para el fortalecimiento de los saberes ancestrales de los pueblos originarios. Popayán: CRIC, 2014.

Consejo Regional Indígena del Cauca. Legislación Indígena. D.C. Bogotá: CRIC/ PEBI, 2014.

Correa Rubio, Francois. "La modernidad del pensamiento indigenista y el Instituto Nacional Indigenista de Colombia”. En Maguaré, No. 21 (2007): 19-63.

Dietz, Gunther y Laura Selene Mateos Cortés. “Una década de educación intercultural en México: debates entre empoderamiento indígena y transversalización de la diversidad". En Educación intercultural a nivel superior: reflexiones desde diversas realidades latinoamericanas. Editado por Sergio Enrique Hernández Loeza, María Isabel Ramírez Duque, Yumen Manjarrez Martínez y Aarón Flores Rosas. México: UIEP/UCIRED/UPEL, 2013, 11-34.

Gentili, Pablo. Pedagogía de la igualdad. Ensayos contra la educación excluyente. Buenos Aires: Siglo XXI Editores-Clacso, 2011.

Giménez, Gilberto. Identidades Sociales. México: Consejo Nacional para la Cultura y las Artes, Instituto Mexiquense de Cultura, 2009.

Gobierno Nacional. Acuerdo Final entre el Gobierno Nacional y el Movimiento Armado Quintín Lame. Editores Amparo Díaz y Darío Villamizar. D.C. Bogotá: Quebecos Impreandes, 1999, 53-67.

Gupta, Akhil. "Fronteras borrosas: el discurso de la corrupción, la cultura de la política y el estado imaginado". En Antropología del Estado. Editado por Aradhana Sharma y Akhil Gupta. México: Fondo de Cultura Económica, 2015, 71-145.

Gutiérrez, Natividad. Mitos nacionalistas e Identidades Étnicas: los intelectuales indígenas y el Estado mexicano. México: Instituto de Investigaciones Sociales, UNAM, 2012.

Herrera Labra, Graciela. "Los docentes indígenas. Breve historia". Reencuentro, 33 (2002): 31-39.

Hirmas, Carolina, Ricardo Hevia, Ernesto Treviño y Pablo Marambio. Políticas educativas de atención a la diversidad cultural: Brasil, Chile, Colombia, México y Perú. Editado por Pablo Marambio. Santiago: OREALC/UNESCO, 2005.

Lao Montes, Agustín. “Cartografías del campo político afrodescendiente en América Latina". Universitas Humanística, 68 No. 2 (2009): 207-245.

López, N. La educación de los pueblos indígenas y afrodescendientes. Informe sobre tendencias sociales y educativas en América Latina 2011. Buenos Aires: Instituto Internacional de Planteamiento de la Educación IIPE-UNESCO, 2011.

Malkún Castillejo, William. "La reforma educativa de 1870 en el Estado soberano de Bolívar". En Revista Amauta, 1, no. 15 (2010): 137-156. 
Medina Betancur, Carlos. "La autonomía educativa indígena en Colombia". Vniversitas, 124 (2012): 261-292.

Ministerio de Educación Nacional. Resolución número 9549 de julio 31 de 1986. D.C. Bogotá: Ministerio de Educación Nacional, 1986.

Moreno Yáñez, Segundo. Alzamientos indígenas en la audiencia de Quito, 1534- 1803. Quito: Abya-Yala, 1989.

Morquecho, Gaspar. El Congreso Diocesano Pastoral de la Madre Tierra. México: Agencia Latinoamericana de Información, 2014. http://www.alainet.org/es/ active/70495 (19 de enero, 2016).

Peñaranda, Daniel Ricardo. Capítulo I: “La organización como expresión de resistencia". En Nuestra vida ha sido nuestra lucha. Editado por Beatríz Acevedo. D.C. Bogotá: Taurus, Semana, Centro de Memoria Histórica, 2012, 19-50.

Peñaranda, Daniel Ricardo. Capítulo V: “Las guerras de los años ochenta y la resistencia contra los actores armados". En Nuestra vida ha sido nuestra lucha. Editado por Beatriz Acevedo. D.C. Bogotá: Taurus, Semana, Centro de Memoria Histórica, 2012, 167-202.

Presidente de la República de Colombia. Decreto 088 de 1976. D.C. Bogotá: Diario Oficial, febrero de 1976.

Presidente de la República de Colombia. Decreto 1142 de 1978. D.C. Bogotá: Diario Oficial de la Federación, 10 de julio de 1978.

Presidente de la República de Colombia. Decreto Número 85 de 1980. D.C. Bogotá: Diario Oficial, 27 de febrero de 1980.

Presidente de la República de Colombia. Decreto 2762 de 1980. D.C. Bogotá: Diario Oficial, 31 de octubre de 1980.

Quijano, Aníbal. “El "movimiento indígena” y las cuestiones pendientes en América Latina" Argumentos, 50 (2006): 51-77.

Rodríguez Reinel, Sonia Mercedes. "La política educativa (etnoeducación) para los pueblos indígenas en Colombia a partir de la Constitución de 1991”. Tesis de Maestría en Antropología, Universidad Nacional de Colombia, 2011.

Rojas, Axel y Elizabeth Castillo. Educar a los otros: políticas educativas y diversidad cultural en Colombia. Popayán: Universidad del Cauca, 2004.

Romero, José Luis. “Las ciudades burguesas”. En Latinoamerica: las ciudades y las ideas, 5a ed. México: Siglo XXI Editores, 2001, 247-318.

Solís, Daniel y Patricia Martínez. Todos somos diferentes: pero aquí en la escuela somos iguales. México: Plaza y Valdés y UASLP, 2012.

Sosa, Margarita y Cristina Henríquez. Instituto Nacional Indigenista - Comisión Nacional para el Desarrollo de los Pueblos Indígenas 1948-2012. México: CDI, 2012. http://www.cdi.gob.mx/dmdocuments/ini-cdi-1948-2012.pdf (7 febrero, 2016).

Torres, Carlos. “Estado, privatización y política educacional. Elementos para una crítica del neoliberalismo". En Pedagogía de la exclusión. Crítica al neoliberalismo en educación. Editado por Juan Antonio Rosado y Marcela Solís Quiroga. México: UACM, 2004, 161-202. 
Tuirán, Rodolfo y Susana Quintanilla. 90 años de educación en México. México: FCE, 2012.

Uribe-Urán, Víctor. “Movimientos indígenas, constituciones, justicia plural y democracia en América Latina". En Justicia, política y derechos en América Latina. Editado por Juan Manuel Palacio y Magdalena Candioti. Buenos Aires: Prometeo Libros, 2007, 83-104.

Villoro, Luis. "Del Estado homogéneo al Estado plural”. En Estado plural, pluralidad de culturas. México: UNAM/Paidós, 1998, 13-62.

Villoro, Luis. Tres retos de la sociedad por venir: justicia, democracia, pluralidad. México: Siglo XXI, 2009.

\begin{tabular}{l|l|} 
& \\
\hline Rodríguez Ugalde, Diana Cecilia. “Identidades políticas \\
emergentes: el profesorado indígena como sujeto colectivo en \\
México y Colombia (Periodo colonial-1990)". Revista Historia de la \\
Educación Latinoamericana. Vol. 19 No. 29 (2017): 135-163.
\end{tabular}

